\title{
Fit for Purpose: A Form and Function-Based Taxonomy for Prevention is Arguably More Refined, Accurate, and Predictive
}

\author{
David R. Foxcroft
}

Published online: 8 February 2014

(C) Society for Prevention Research 2014

I am grateful for the opportunity to reflect and respond to the commentaries of Drs. Burkhart and Biglan. I am in agreement with most of what they say, particularly, the point that environment is a key determinant of health risk behavior and as such, should be a main focus for prevention action.

Dr. Burkhart makes a number of points (Burkhart 2013), and I'd like to respond to the two that I find the most significant and challenging to the ideas in my article (Foxcroft 2013). ${ }^{1}$ Gregor argues that environmental prevention should be considered a form of prevention rather than a function, based on the idea that environmental prevention is about changing the context for behavior, and sits alongside the three other forms, universal, selective, and indicated, which rely on persuasion to achieve prevention.

However, my argument is that the grouping together of different contexts for behavior within a broad "environmental prevention" category is not sufficiently refined. For example, family norms and socialization are defined by Gregor as environmental prevention; but family norms and socialization do not provide a direct context for behavior; rather, they provide an indirect context via the internalization of norms, values, and habits over months and years of parenting. This, in turn, puts young people onto different developmental trajectories where the norms,

${ }^{1}$ In his insightful and detailed commentary, Dr Burkhart makes a number of helpful suggestions for attributes that could possibly have been considered within the scope of the new taxonomy. Many of these have indeed been thought about, but were not included in the paper for the sake of brevity and clarity. In this response, I have not written about these sins of omission, but instead I have focused on the possible sins of commission pointed out by Gregor, i.e., more fundamental challenges to the proposed form and function taxonomy.

D. R. Foxcroft $(\bowtie)$

Oxford Brookes University, Oxford, UK

e-mail: david.foxcroft@brookes.ac.uk values, and behavioral skills they hold lead to different adaptive or maladaptive behaviors.

Moreover, I am not convinced that the distinction between context (environmental) and persuasion (universal, selective, indicated) is sufficiently robust. Taking the above example, a prevention intervention that influences family norms and socialization in a higher-risk family target group clearly and accurately fits the concept of selective prevention as proposed by Gordon (1983) and endorsed by the National Research Council and Institute of Medicine (2009). I'm afraid I do not agree with the idea that we should change this system and label such interventions as "environmental prevention." In my proposal, such a prevention intervention would be classified as developmental and selective, which I suggest is both more refined and more accurate.

Dr. Biglan raises two issues (Biglan 2014); the first concerns the precision of the taxonomy and the second, its predictive utility. The taxonomy is, as yet, untested beyond the case study reported in the article, so reliable coding of the proposed functional types is not yet available. There is precedent for reliable coding of the content of complex interventions in the assessment of behavior change techniques (Abraham and Michie 2008), and this approach offers promise for the coding and assessment of the content and efficacy of the different functional types of prevention.

Alongside this approach, I would also venture that the predictive utility of the functional taxonomy could be informed by a re-appraisal of the major theories underlying many prevention interventions. In a separate article (Foxcroft in press), I have argued that a theoretical perspective that deserves much more attention within the prevention science community is the idea that objects in the environment largely trigger behavior, and that cognitive aspects (e.g., attitudes/intentions) are mostly secondary to behavior that emerges from the transaction between an individual and their environment. Simply put, the 
notion that "brain follows behavior" (Marsh et al. 2009) is arguably a more compelling basis for prevention science and action, undermining cherished theories that specify attitudes and intentions as the proximal determinant of behavior (Sniehotta et al. 2014).

One leading contemporary theorist has proposed that behavior typically results from "action-oriented predictive processing" (Clark 2013); essentially, the idea is that individuals respond instinctively and automatically to their environment, without any higher-level cognitive mediation of action. The exception to this typical pattern occurs when action, or opportunities for action, within a particular environmental context is not consistent with prior expectations in which case individuals are motivated to change their behavior or their expectations to reduce this inconsistency. Daniel Dennett (2013) has linked this theory to the Umwelt concept and to Gibson's (1979) notion of affordances.

Importantly, for the proposed functional types of prevention, there is a clear "action-oriented predictive processing" theoretical link to be made between (1) environmental context and environmental prevention, where limiting opportunities for action can lead to changes in behavior and consequent changes in attitudes, norms, values, habits, etc.; and (2) prior expectations and developmental prevention, where attitudes, norms, values, habits, etc. are internalized over months and years of socialization and make a significant contribution to prior expectations. By contrast, it is not clear how informational prevention, with a focus on changing knowledge and awareness, can have a direct and strong impact on risk behavior that is determined by largely automatic, unconscious, action-oriented predictive processing.

With this theoretical re-appraisal in mind, I have predicted (Foxcroft in press) that strong environmental prevention interventions are generally more effective than developmental prevention which, in turn, is generally more effective than informational prevention. This prediction assumes that implementation or enforcement of prevention interventions across all functional types is equally robust. Moreover, within each functional type, there will be interventions that are more or less effective (see Foxcroft in press for details).
I am grateful to Drs. Burkhart and Biglan, and to the Editors of Prevention Science, for the opportunity to communicate and reflect on these ideas. I hope this is the beginning of an ongoing discussion that improves our conceptualization and understanding of effective prevention.

\section{References}

Abraham, C., \& Michie, S. (2008). A taxonomy of behaviour change techniques used in interventions. Health Psychology, 27, 379-387. doi:10.1037/0278-6133.27.3.379.

Biglan, A. (2014) Comments on Dr Foxcroft's classification system. Prevention Science. doi:10.1007/s11121-014-0464-4.

Burkhart, G. (2013). Is environment really a function? Prevention Science. doi:10.1007/s11121-013-0452-0.

Clark, A. (2013). Whatever next? Predictive brains, situated agents, and the future of cognitive science. Behavioural and Brain Sciences, 36, 181-253. doi:10.1017/S0140525X12000477.

Dennett, D. C. (2013). Expecting ourselves to expect: The Bayesian brain as a projector [Commentary]. Behavioural and Brain Sciences, 36, 209-210. doi:10.1017/S0140525X12002208.

Sniehotta, F. F., Presseau, J., \& Araújo-Soares, V. (2014). Time to retire the theory of planned behaviour. Health Psychology Review. doi:10. 1080/17437199.2013.869710.

Foxcroft, D. R. (2013). Can prevention classification be improved by considering the function of prevention? Prevention Science. doi:10. 1007/s11121-013-0435-1.

Foxcroft, D.R. (in press) "Form ever follows function. This is the law". A prevention taxonomy based on a functional typology. Adicciones.

Gibson, J. J. (1979). The ecological approach to visual perception. New Jersey, NJ: Lawrence Erlbaum Associates.

Gordon, R. S. (1983). An operational classification of disease prevention. Public Health Reports, 98, 107-109.

Marsh, K. L., Johnston, L., Richardson, M. J., \& Schmidt, R. C. (2009). Toward a radically embodied, embedded social psychology. European Journal of Social Psychology, 39, 1217-1225. doi:10. 1002/ejsp.666.

National Research Council and Institute of Medicine. (2009). Preventing mental, emotional, and behavioral disorders among young people: progress and possibilities. Committee on Prevention of Mental Disorders and Substance Abuse among Children, Youth and Young Adults: research advances and promising interventions. In M. E. O'Connell, T. Boat, \& K. E. Warner (Eds.), Board on Children, Youth, and Families, Division of Behavioral and Social Sciences and Education. Washington, DC: The National Academies Press. 